\title{
Controvérsias do Desenvolvimento dos Assentamentos Rurais em São Paulo: produção para os biocombustíveis e as alternativas de programas municipais
}

Controverses of the development of rural settlements in São Paulo: production for biofuels and the alternatives of municipal programs

Des controverses relatives à les Assentamentos Ruraux établis dans l'État de São Paulo-Brésil: la producion des biocarburants vis-à-vis aux propositions alternatives concernant des programmes municipaux de développement socio-économique Controversias del Desarrollo de los Asentamientos Rurales en São Paulo: producción para los biocombustibles y las alternativas de programas municipales

\author{
Vera Lucia Silveira Botta Ferrante* \\ Luís Antonio Barone** \\ Luiz Manoel de Moraes Camargo Almeida***
}

Recebido em 2/3/2009; revisado e aprovado em 2/12/2009; aceito em 20/2/2010

\begin{abstract}
Resumo: Este artigo discute os dilemas e as contradições das atuais experiências de assentamentos rurais, a partir da trama de tensões gerada entre distintos agentes, estratégias e racionalidades. Analisa as alternativas controversas à integração no sistema produtivo agroindustrial do biodiesel e as perspectivas de programas municipais dirigidos a assentados e pequenos produtores. Discutem-se as possibilidades dessas opções para o presente/futuro dessas experiências, em duas regiões, com perfis diferenciados de desenvolvimento regional.

Palavras-chaves: Assentamentos Rurais. Biocombustíveis. Políticas de Desenvolvimento Rural.
\end{abstract}

Abstract: This paper discusses the dilemmas and the contradictions of the current experiences of rural settlements, based on the net of tensions which are generated among different agents, strategies and rationalities. It analyzes the controversial alternatives to the integration in the agroindustrial productive system, of the biodiesel and the perspectives of municipal programs directed to rural settlers and to small producers. It discusses the possibilities of these options for the present/future of these experiences in two regions with different profiles of regional development.

Key-words: Rural Settlements. Biofuels. Rural Development Poli.

Resumen: Este artículo discute los dilemas y las contradicciones de las actuales experiencias de asentamientos rurales, a partir de la trama de tensiones producida entre distintos agentes, estrategias y racionalidades. Analisa las alternativas controversas a la integración en el sistema productivo agroindustrial, del biodiesel y las perspectivas de programas municipales dirigidos a asentados y pequeños productores. Se discute las posibilidades de esas opciones para el presente/futuro de esas experiencias en dos regiones con perfiles distintos de desarrollo regional.

Palabras clave: Asentamientos rurales. Biocombustibles. Políticas de Desarrollo Rural.

Résumé: L'objectif de notre texte est de mettre en discussion les dilemmes construits à partir des expériences relatives à les Assentamentos Ruraux et leur agencement en tant que tensions sociales engendrées par des agents et leurs stratégies et rationalités distinctes. Il s'ensuit qu'on fait l'analyse juste à l'actualité des alternatives polémiques à propos de l'intégration dans le système agro-business productif du biodiesel par rapport aux programmes socioéconomiques municipaux vers directement les assentados et les petits producteurs. Nous en présentons quelques-unes des possibilités pour le présent / futur dans deux régions dont leur profil est tout à fait différent.

Mots-clés: Biocarburants. Politiques pour le Développement Rural. Assentamentos Ruraux.

\section{Um itinerário de questões polêmicas}

A luta pela terra e a consequente política de assentamentos rurais desenvolvida no Estado de São Paulo nos últimos 20 anos tem colocado, tanto para pesquisadores quanto para gestores públicos e população assentada, questões e desafios no desenvolvimento de experiências de democratização do acesso à terra na unidade mais modernizada da federação. Paralelamente, o setor agroindustrial ligado à produção de açúcar e álcool combustível (etanol) tem, neste Estado brasileiro, sua base mais importante. A presença constatada da cultura agroindustrial da cana-de-açúcar nos Projetos de Assentamentos (P.A.s)

\footnotetext{
* Pesquisadora do CNPq, Coordenadora do Mestrado em Desenvolvimento Regional e Meio Ambiente do Centro Universitário de Araraquara (Uniara). E-mail: mestrado@uniara.com.br.

** Professor Doutor do Departamento de Planejamento da FCT/UNESP - Presidente Prudente-SP. E-mail: laborone@uol.com.br.

*** Pesquisador do Mestrado de Desenvolvimento Regional e Meio Ambiente. Uniara, Araraquara-SP. E-mail: manoel77@yahoo.com.br.
} 
paulistas constitui um dilema que expõe o futuro destas experiências de Reforma Agrária a controvérsias de natureza diversa, o que exige um olhar atento e crítico sobre esta trajetória.

Igualmente, registra-se que, atualmente, a produção para fornecimento às indústrias de biocombustíveis acontece em duas regiões do Estado - região Nordeste e região Oeste (esta última mais conhecida como Pontal do Paranapanema). Embora ambas contem com a produção de cana-de-açúcar agroindustrial, apenas no Pontal foi implantado um projeto de produção para o biodiesel.

As duas alternativas, polêmicas, exigem um cuidadoso acompanhamento em face dos bloqueios e perspectivas que se apresentam para os assentamentos (MEDEIROS e LEITE, 2004), as trajetórias, tanto dos trabalhadores quanto da expansão da cana de açúcar - e de culturas para a produção de biodiesel - no interior dos assentamentos ganham uma maior inteligibilidade a partir da leitura das tramas de tensões das quais são partes constitutivas. A trama, nesse caso, é a constituída pelas relações travadas entre distintos atores, sendo destacados, nesse estudo, os próprios assentados e os diferentes mediadores, tanto das políticas públicas como das possíveis alternativas econômicas e políticas. O confronto desses atores nos espaços sociais de disputa e constituição das políticas públicas é gerador dessa trama de tensões, opondo interesses e racionalidades diversas, mediante distintos projetos, compromissos e estratégias.

Nos termos em que essas relações de parcerias vêm se concretizando, este trabalho vai discutir a necessidade de desconstrução desse conceito calcado na matriz teórica de capital social e a importância de submeter ao crivo analítico as desigualdades constitutivas desta polêmica integração dos assentados às usinas de açúcar e álcool, bem como a construção possível de uma agenda de políticas públicas de segurança alimentar e da produção de biodiesel pautada nos princípios da produção agroecológica, na valorização da produção regional e na inclusão social de produtores familiares assentados e trabalhadores rurais.

Os assentamentos rurais, experiências inovadoras na gestão do território, expressam tensões que são reveladoras das contradições e possibilidades de uma certa agricultura familiar perante o poder do capital agropecuário e agroindustrial, no âmbito do desenvolvimento social no campo. Nestes, os assentados aparecem como sujeitos muitas vezes em posição de subalternidade, porém com presença ativa e desenvolvendo estratégias, mais ou menos coerentes, de possíveis projetos políticos de fortalecimento da agricultura familiar via assentamentos. Outras vezes, parecem tão somente submergir num sistema de controles e de poderes que os aniquilam. Essa ambiguidade está bastante presente nas distintas maneiras pelas quais usinas, órgãos técnicos, agências de mediação e trabalhadores assentados se posicionam na discussão e no encaminhamento das ações no tocante a plantar ou não plantar cana ou oleaginosas para as agroindústrias.

As alternativas que envolvem a aceitação ou a recusa em plantar cana para usinas têm que ser surpreendidas como parte das relações complexas que envolvem assentados, as instâncias do poder local, a economia regional e as agências de mediação. Este conjunto, no entanto, tem que ser pensado de uma perspectiva político-social integradora, não unicamente por uma determinação econômica. Controvérsias é que não faltam na discussão dessa questão que entra necessariamente na agenda das reflexões sobre o presente/futuro dos assentamentos rurais, os quais têm como referência, neste artigo, duas regiões do Estado de São Paulo, diferenciadas em suas relações e em sua dinâmica.

\section{Fragmentos da caracterização dos assentamentos}

\subsection{No território das agroindústrias}

Produto de diferentes políticas públicas gestadas ao longo dos últimos 20 anos, a região de Araraquara (região central do Estado de São Paulo) conta com três projetos de assentamentos rurais, sendo dois deles de responsabilidade do Instituto de Terras do Estado/ITESP (P.A.s Monte Alegre e Horto Bueno de Andrade) e um do INCRA (P.A. Bela Vista do Chibarro).

Os primeiros núcleos de assentamentos (Monte Alegre I, II, III e IV) foram instalados pelo ITESP nos anos de 1985 e 1986, ainda 
na gestão do governador André Franco Montoro (1983-1986), tendo sua instalação se completado quase dez anos depois. Hoje o projeto de assentamento Monte Alegre conta com seis núcleos, perfazendo um total de 416 lotes agrícolas e, segundo o ITESP, 418 famílias residentes nessa antiga propriedade da FEPASA (Ferrovias Paulistas S.A.).

Além desses núcleos do ITESP, existe um projeto de assentamento promovido pelo governo federal (INCRA) no município de Araraquara: o projeto de assentamento Bela Vista do Chibarro, com 176 lotes agrícolas e (estimadamente) o mesmo número de famílias. O Projeto de Assentamento Bela Vista se encontra em terras anteriormente pertencentes a uma usina de açúcar (Usina Tamoio), cuja desapropriação data de 1989. A mobilização que levou à instalação deste P.A. acaba sendo emblemática da luta dos trabalhadores rurais nas terras dos canaviais (FERRANTE, 1992).

A trajetória dessas experiências de assentamentos não se diferencia muito das demais, sobretudo no Estado de São Paulo, no tocante à ação dos órgãos públicos responsáveis pelos projetos. A falta de planejamento, a desorganização de um cronograma racional de investimentos e o esvaziamento cíclico da estrutura de assistência técnica (FERRANTE e BARONE, 1997/1998) acabam por prejudicar em muito o desenvolvimento econômico dos produtores assentados. Conflitos entre assentados ligados a distintas direções políticas, expressos em protestos contra os órgãos técnicos, conflitos que tiveram interferência nas experiências frustradas de cooperativas e de associações reavivados por muitas disputas internas fazem parte desta trajetória.

Em comparação com inúmeros outros projetos, tanto sob responsabilidade do governo estadual quanto do governo federal, a característica mais marcante desses assentamentos é justamente sua inserção territorial numa região de agricultura modernizada, praticamente monopolizada pelas culturas da cana-de-açúcar e de citros. A maior parte das terras agricultáveis da região está cultivada com cana - cuja extensão chega, no município de Araraquara, a cerca de 32 mil hectares - e cuja cadeia produtiva constitui o maior complexo agroindustrial da região ${ }^{1}$.

\subsection{Nas terras do "boi gordo"}

Na região conhecida como Pontal do Paranapanema (extremo Oeste Paulista) a questão fundiária tem sido - ao longo de décadas - o ponto fulcral definidor das políticas públicas e ingrediente básico das tensões sociais envolvendo o estado e diferentes classes sociais. A região é, portanto, de importância ímpar quando se aborda a temática da reforma agrária no Estado de São Paulo. Com uma ocupação que data do final do século XIX, o Pontal do Paranapanema revela, em seu histórico fundiário, o mais conhecido caso de grilagem de terras do país (LEITE, 1999).

Centenas de ocupações, milhares de trabalhadores mobilizados e acampados, dezenas de ações judiciais discriminatórias promovidas pelo Estado no sentido de identificar e arrecadar as terras devolutas irregularmente ocupadas: esse é o contexto sociopolítico do Pontal do Paranapanema, hoje a região do Estado de São Paulo com o maior número de assentamentos e de famílias assentadas. Nesse cenário, o incremento da política de assentamentos na região aconteceu, sobretudo, na primeira gestão do governador Mário Covas (PSDB, 1995-1998), como resultado de intensas negociações para arrecadação de áreas e o assentamento de milhares de famílias. Dada a importância da região do Pontal do Paranapanema com relação ao número de assentamentos (em 2008, eram 103 Projetos de Assentamentos já instalados, com aproximadamente 5,5 mil famílias assentadas), essa área do Estado tem mostrado uma dinâmica extremamente rica no que tange a essa questão.

\section{$3 \mathrm{O}$ modo de vida dos assentamentos e a "parceria" com as agroindústrias}

Dados recentes da Fundação ITESP (Quadro 1) revelam que, em 2008, mais de 350 assentados em projetos da jurisdição do governo estadual, distribuídos pelas regiões Nordeste e extremo Oeste do Estado, têm contratos para fornecimento de cana a diferentes usinas ${ }^{2}$. Essa distribuição geográfica apresenta situações distintas na constituição das tramas sociais que suportam essa relação. 


\begin{tabular}{|c|c|c|c|}
\hline Grupo Técnico & Agroindústria & Projeto de Assentamento & N. de assentados \\
\hline Araraquara & $\begin{array}{c}\text { Usina Santa Luiza - Motuca } \\
\text { Usina Maringá - Araraquara e } \\
\text { Usina São Martinho - Pradópolis em } \\
\text { processo de oficialização da parceria }\end{array}$ & $\begin{array}{l}\text { Monte Alegre } \\
\text { Bueno de Andrade } \\
\text { Silvânia } \\
\text { Guarany }\end{array}$ & $\begin{array}{l}212 \\
\text { (total de contratos com } \\
\text { a Usina Sta. Luiza) }\end{array}$ \\
\hline \multirow{4}{*}{$\begin{array}{l}\text { Teodoro } \\
\text { Sampaio }\end{array}$} & \multirow{4}{*}{ Destilaria Alcídia S/A } & Santa Zélia & 18 \\
\hline & & Sta. T. da Alcídia & 6 \\
\hline & & Alcídia da Gata & 4 \\
\hline & & Sta. Cruz da Alcídia & 3 \\
\hline Rosana & Destilaria Alcídia S/A & Gleba XV de Novembro & 38 \\
\hline \multirow{2}{*}{ Bebedouro } & Usina Andrade Açúcar e Álcool S/A & Ibitiúva & 24 \\
\hline & Usina Viralcool S/A & Reage Brasil & 46 \\
\hline
\end{tabular}

Quadro 1 - Distribuição dos assentamentos geridos pelo ITESP que implantaram cana de açúcar para fornecimento a agroindústrias . Fonte: Fundação Itesp, 2008.

Poderíamos associar a complexa transformação dos assentamentos rurais em espaços para a produção de cana à possível falência das experiências de reforma agrária, já que a expansão de cana sugere a reprodução da monotonia da paisagem das monoculturas e das degradadas condições de trabalho a que são submetidos os cortadores de cana, movimento que se põe na contramão das perspectivas de autonomia sugeridas pelas políticas de assentamentos. Se tomarmos a relação dos assentamentos com o ideário do desenvolvimento pautada por tensões que se expressam no modo de vida e na maneira de inserção dos assentamentos nos contextos regionais, como interpretar a expansão da cana nesses espaços? Como ficam as contradições e possibilidades de um tipo de agricultura familiar diante dos constrangimentos estruturais das economias regionais e do entorno sociopolítico? A progressiva presença da cana nos assentamentos seria demonstração do predomínio de ações de acomodação dos assentados em face do ideário de integração econômica aos sistemas produtivos regionais?

No caso da discussão ora travada, a trama de relações e tensões se constitui um campo específico, no qual estão em disputa tanto os possíveis distintos projetos de desenvolvimento dos assentamentos rurais quanto a hegemonia política no território local/microrregional, ela mesma bastante definidora dos referidos projetos de desenvolvimento. Questões ligadas à cana e às oleaginosas para os biocombustíveis nos assentamentos interferem significativamente no presente/ futuro dessas experiências.

Na situação dos assentados que fornecem cana às usinas, o termo "parceria" aparece referido a uma portaria da Fundação Instituto de Terras do Estado de São Paulo "José Gomes da Silva" - Itesp (Portaria Itesp n. 75 de 24/10/2002, revogada pela Portaria n. 77 de 27/7/2004). Trata-se, portanto, de um termo utilizado pelos órgãos gestores para definir a política de desenvolvimento dos assentamentos rurais. Dentre os programas que poderiam proporcionar o desenvolvimento sustentável das comunidades assentadas, aparece a referência à formação de

[...] "parcerias negociais" visando alocar recursos e dinamizar o processo de capitalização das famílias beneficiárias dos projetos de assentamento, objetivando sua autonomia, sustentabilidade, maior participação na economia dos municípios e suprimento de matéria-prima para as agroindústrias. (grifo nosso)

Estas expectativas vão se confrontar com a situação concreta da parceria com os assentados, expressão institucional de um contrato, no qual são detectadas relações assimétricas de poder. São as desigualdades constitutivas desta relação responsáveis pela controversa integração dos assentados às parcerias com as usinas de açúcar e álcool. Estamos bem longe também da situação clássica de "parceria", descrita por Antonio Candido (1987). N'Os parceiros do Rio Bonito, encontramos o que poderíamos chamar de uma forma de arrendamento em 
espécie, unindo proprietários e parceiros num universo social no qual as distâncias sociais e as distorções na gestão do negócio são pequenas. Nos assentamentos, está em questão uma forma de arrendamento totalmente mercantil, que se tenta disfarçar de variadas maneiras, às vezes com algum regramento oficial na transação (no caso dos canaviais implantados segundo Portaria do Itesp).

Expressando efetivamente uma desigualdade de condições, a parceria tem sido desconfigurada pelas práticas adotadas. Nessa reconstrução sociológica, a "parceria" com as agroindústrias, nos termos em que ela vem se concretizando, exige a sua desconexão da matriz conceitual de "capital social", que tem, como princípio, parcerias sociais embasadas em valores como "solidariedade", "reciprocidade", "cooperação" e "confiança" (PUTNAN, 2000).

\section{A parceria no cenário dos assentamentos: o vai-e-vem da entrada da cana nos assentamentos rurais na região de Araraquara}

Há mais de quinze anos, a proposta de um "consórcio" para produção de cana agroindustrial no assentamento Monte Alegre envolveu a Prefeitura de Motuca, uma usina localizada no município e órgãos do Estado, gerando desdobramentos e divisores de águas, pondo em discussão o modo de vida constituído nos assentamentos, a perspectiva da agroindústria conviver com espaços diversificados de produção/reprodução social e, especialmente, o significado da cana como possível estratégia de permanência na terra. A trajetória produtiva dos agricultores assentados nessa região oscilou, desde meados da década de 1980, entre a produção de grãos nos anos iniciais, uma busca por diversificação agrícola que vai da fruticultura a algumas experiências isoladas de produção orgânica, chegando a uma mal resolvida (política e juridicamente) integração ao complexo agroindustrial sucroalcooleiro.

Desde então, a pressão que as usinas exercem sobre os projetos de assentamentos a fim de que se dediquem à produção canavieira, passando a ser fornecedores de matéria prima para as agroindústrias nunca se interrompeu efetivamente. De forma mais ou menos dissimulada, a proximidade e o cercamento das usinas se constituiu, nos últimos anos, em uma sombra a nublar a perspectiva de uma produção pluralista e diversificada nos assentamentos da região.

Após anos de debates e polêmica, o ITESP, através da portaria referida, estabeleceu parcerias entre lotes agrícolas dos assentados e agroindústrias, sob o argumento de dinamização do processo de capitalização das famílias beneficiárias dos projetos de assentamentos. Justificou a portaria que acabou por consentir, sob regras, o plantio da cana, como perspectiva de garantir maior participação dos assentados na economia dos municípios.

Foi mantido o limite de $50 \%$ da área total nos lotes com área até 15 ha, nos lotes com área superior a 15 ha estipulou-se até $30 \%$ da área total. A determinação de que a exploração deveria ser feita de forma individual, associativa ou coletiva, ficando proibida outra modalidade de exploração que não permitisse a participação direta dos beneficiários no planejamento, condução e comercialização da produção contrastou com o que passou a ocorrer. O Itesp, de fato, nunca controlou tais limites. Há manifestações de resistência, agravadas no caso das queimadas que passam a entrar, sem pedir licença, nas casas e nos lotes dos assentados.

No outro espaço estudado em Araraquara, o assentamento Bela Vista do Chibarro, sob jurisdição do INCRA, há denúncias de que os assentados começaram a arrendar suas terras, desde o início dos anos 2000. O INCRA manteve-se, em tese, contrário ao plantio de cana, embora sua omissão fosse patente, durante anos a fio.

Nos últimos anos, o Incra tem procurado retomar seu papel gestor de fato. Isto se expressou concretamente na instalação de um escritório do órgão em Araraquara (em 2005), que acabou por solicitar a reintegração de posse nos lotes irregulares ou totalmente arrendados às usinas. Esta situação tem acirrado os conflitos e parece se sobrepor a qualquer perspectiva de cooperação. A posição do INCRA tem sido, atualmente, frontalmente contrária ao plantio de cana. Iniciativas, ainda que tímidas, de alternativas de produção/reprodução social têm sido propostas pelo INCRA, que tem buscado, na 
parceria com o movimento sindical e com a Prefeitura Municipal de Araraquara, construir outro caminho para o assentamento Bela Vista do Chibarro. Construção que tem enfrentado conflitos e cisões.

Após um conflituoso despejo judicial, ocorrido em dezembro de 2007, busca-se orquestrar um movimento de abandono das parcerias não legais com as usinas neste assentamento. Assim, em meados de 2008, 50 assentados da Bela Vista solicitaram a ruptura de contrato com a Usina Zanin (principal compradora/plantadora de cana no assentamento), com a erradicação da cana-deaçúcar existente em seus lotes.

O movimento que vem sendo observado de rompimento das parceiras pode ser visto, por um ângulo, como uma tentativa de reapropriação do espaço dos assentamentos pelos assentados. Pode ser, por outro lado, uma reação acomodatícia, provocada pelo receio de sofrerem ações de reintegração de posse por parte do órgão gestor, semelhantes às sofridas por um grupo de famílias em dezembro de 2007. O futuro dessa iniciativa ainda é incerto, posto que bastante recente.

\section{Nas terras de Teodoro Sampaio, a cana pede passagem}

A primeira iniciativa de produção de cana para fornecimento agroindustrial nos assentamentos do Pontal do Paranapanema teve início em 1993, no assentamento Água Sumida, em Teodoro Sampaio. Apesar de constar, em relatório oficial da época, que se tratava de um projeto-piloto para apenas 11 produtores (9\% de 121 assentados), este mesmo documento dá conta que " 27 beneficiários teriam interesse em implantar a cana" ${ }^{4}$. A mobilização, puramente institucional, em torno desta questão resultou em uma permissão oficial para o grupo de $11 \mathrm{e}$ outra, oficiosa, para todos os demais interessados. Registra-se que os documentos do INCRA, do ITESP e da Unesp ${ }^{5}$ foram todos inconclusivos, no geral assumindo uma postura ambígua entre a condenação à produção para a agroindústria sucroalcooleira e o reconhecimento da expectativa de segurança econômica dos assentados envolvidos.

Como agente privilegiado nesse processo, encontra-se a Destilaria Alcídia, também localizada em Teodoro Sampaio. Além de promotora do projeto "especial" no P.A. Água Sumida, a Alcídia continuará sendo, ao longo de anos a fio, a principal empresa processadora da cana fornecida pelos assentados da região.

Enquanto na região de Araraquara a tentativa de implantação da cana com destinação agroindustrial sempre foi envolvida em forte polêmica, tendo o movimento sindical rural como antagonista das diferentes propostas para que assentados destinem suas terras à cana, no Pontal, o principal núcleo articulador político dos assentados (o MST) não detinha forte presença nos assentamentos nos quais a Destilaria Alcídia buscou plantar cana e pouco fez, concretamente, para confrontar essa ação. Essa falta de contrapressão política explica, ao menos em parte, a facilidade com que a empresa atuou junto aos assentados e técnicos oficiais.

A partir de um declínio na renda obtida na cana entre 1999 e 2000, os assentados foram levados a não renovar os plantios. Esta experiência de integração ao complexo agroindustrial da cana foi encerrada por volta de 2002. Ramos (2005), que entrevistou os assentados que plantaram cana, cita que estes não rechaçam totalmente a experiência, considerando que ela foi financeiramente vantajosa por algum tempo e que, se fossem repetir essa cultura, buscariam maior controle no contrato e nos mecanismos de avaliação da cana colhida.

Mais recentemente, assentados dos PAs Santa Terezinha da Alcídia e Alcídia da Gata, vizinhos da área industrial da Alcídia, implantaram a cultura da cana para fornecimento a essa usina. Desta feita, se a empresa processadora é a mesma, as condições de fornecimento da polêmica planta variam.

No caso desses dois mais recentes assentamentos que plantaram cana, essa nova cultura foi implantada mediante a mesma portaria oficial da Fundação ITESP, que regulamentou a exploração sucroalcooleira nos assentamentos de Motuca e Araraquara.

Assim como no caso do PA Água Limpa, não houve uma maior discussão, nem pressões por parte de alguma organização de trabalhadores, sobre os impactos ou o sentido dessa "parceria" da cana. Novamente, 
observa-se que os assentamentos que aderiram a contratos para cultivo de cana-de-açúcar não estão na órbita do MST, principal polo político dos trabalhadores sem-terra e assentados na região. Além disso, a proximidade geográfica da usina (maior ainda que o PA Água Limpa), só fortalece o poder de influência da empresa. No caso do PA Santa Terezinha da Alcídia, no entanto, o fato de a área estar arrendada pela Alcídia serviu, também, para uma "negociação" entre a empresa, os trabalhadores e o ITESP, desde a implantação do $\mathrm{PA}^{6}$.

Verifica-se, através da documentação recolhida na pesquisa de campo, que a implantação da cultura da cana para fornecimento à Destilaria Alcídia, tanto no PA "Alcídia da Gata", quanto no "Santa Terezinha da Alcídia", foi totalmente financiada pelo Pronaf. Além de aproveitar-se de uma brecha de interpretação na Portaria 075 do ITESP - que afirma, no parágrafo $5^{\circ}$ do seu artigo $2^{0}$ que "as áreas dos lotes comprometidas com projetos agropecuários financiados pelo Sistema Nacional de Crédito Rural ou com programas oficiais de fomento não poderão ter implantadas culturas para fins de processamento industrial" esse financiamento contraria o "espírito da lei", ao menos a partir do que foi declarado à pesquisa por um dos redatores da portaria, para quem "ela foi feita para que as usinas não se aproveitem do financiamento subsidiado dos assentados", algo que julgava um "abuso" 7 .

\section{Impactos das parcerias nos assenta- mentos das regiões empíricas}

Para além desse verdadeiro imbróglio administrativo, o resultado financeiro da execução dos projetos de cultivo da cana-de-açúcar para fornecimento à Destilaria Alcídia (região o Pontal do Paranapanema) teve, como no caso dos contratos firmados no P.A. Monte Alegre (região de Araraquara), uma visível disparidade entre a renda prevista e a realizada. Dezoito assentados aderiram ao "consórcio" com a usina e tiveram resultados aquém do previsto no projeto financeiro apresentado ao Banco do Brasil para tomada de crédito: "foi tudo para o banco", disse um dos produtores.
Essa paradoxal condição - ainda mais flagrante porque contextualizada na região do Estado de São Paulo onde mais os trabalhadores sem-terra se mobilizaram - só tende a se agravar, na medida em que o grupo Odebrecht (atual dono da Destilaria Alcídia) está instalando ali mais uma destilaria. Essa nova planta industrial localiza-se no município de Mirante do Paranapanema (o que comporta o maior número de assentamentos do Centro-Sul do Brasil) e, inclusive, já teve sua área ocupada pelo MST - numa jornada realizada em junho/2008. O aumento da área plantada de cana na região é patente e a nova unidade da Odebrecht - chamada "Usina Conquista do Pontal" - será uma nova e incômoda vizinha para outros assentamentos.

$\mathrm{O}$ que tem significado, efetivamente, os contratos feitos pelos assentados em parceria com empresas ou agroindústrias? Existem diferenças marcantes entre as diversas parcerias com o setor privado. Não é incomum, embora de difícil avaliação quantitativa, que assentados negociem parcela de seus lotes para cultivos agroindustriais voltados para a produção de alimentos, sendo o caso da mandioca o mais recorrente. A utilização maior ou menor da mão-de-obra familiar dá a tônica nesta diferenciação. Mesmo nas "parcerias" com as usinas, estão previstas a partir das Portarias do Itesp - a utilização da força de trabalho do assentado em determinadas tarefas do ciclo produtivo. As variações nos mercados específicos de cada produto também são importantes fontes de análise, pois mesmo com contratos assinados, as oscilações dos preços no momento das vendas dão grandes diferenciais na hora de receber pelos produtos. Isto pôde ser constatado nas duas regiões objeto de análise.

No caso da cana-de-açúcar agroindustrial encontramos o exemplo mais complexo de parcerias entre assentados e setor privado. As usinas têm um longo histórico de assédio aos pequenos produtores assentados para o plantio nos lotes, conforme expresso na produção acadêmica voltada a esta temática (STETTER, 2000; FERREIRA JÚNIOR, 2007).

Verificamos outros impactos e consequências da atuação do setor canavieiro, principalmente no que se refere às questões ambientais e sociais afetadas pelo processo produtivo de álcool e açúcar. Dentro da 
parceria com os assentados, plantar a cana implica problemas como a fragmentação interna nos assentamentos entre os que plantam ou não, incluindo-se brigas e violência física. Além de trazer um forte risco de arrendamento da terra, inúmeros problemas relacionados às queimadas e aos demais métodos produtivos têm afetado diretamente a população assentada em seu espaço de moradia e de trabalho.

A diferença de posição que os órgãos gestores (Incra e Itesp) adotaram aprofunda as contradições e ambiguidades dessa realidade. Tais diferenças entre as posições dos órgãos têm demarcado o campo político no contexto da gestão dos projetos de assentamentos no Estado de São Paulo, com acusações mútuas de omissão perante o dilema do desenvolvimento econômico e social desses territórios. Nossa prioridade de análise, no entanto, é a discussão das controvérsias e das armadilhas, muitas vezes dissimuladas, que se apresentam nas sedutoras parcerias propostas pelas usinas aos assentamentos rurais.

Ao contrário do que falavam os técnicos da usina e do Itesp e mesmo alguns assentados empolgados com a cana, a renda conquistada fica, em muitos dos casos, abaixo do esperado. Além disso, os assentados ficam com metade da área de seus lotes presa num contrato de cinco anos - tempo superior ao previsto no Estatuto da Terra - inutilizada para outras culturas se quiserem abandonar a cana. Tal perda de liberdade sobre suas terras já é traduzida hoje pela intenção ou até processos judiciais para anularem o contrato e saírem da parceria, processo complexos, de resultados não imediatos.

Há outros elementos a considerar nesta trama, entre eles, a relação de compadrio que alguns assentados têm com usineiros, o que por vezes os beneficia na hora de "pegar o cheque". Durante uma mesma safra, o lucro de assentados que plantaram no mesmo período, no mesmo volume de área, varia muito. Existem assentados que parecem ser um tipo de representante da usina dentro da parceria, eles controlam as turmas de trabalho que plantam e colhem a cana, as horas de máquinas na preparação da terra. Geralmente alguns deles têm uma antiga relação de trabalho com a usina ou até são funcionários dela.
Esse bom relacionamento - que, no entanto, comporta também uma crítica à exploração imposta pela usina - viabiliza a manutenção da cultura canavieira e recria uma integração sistêmica, conforme estudado em outros contextos envolvendo pequenos fornecedores de cana (NEVES, 1981).

O sistema de controles sociais, como um instituto de poder, não deixa de garantir a acumulação capitalista para a agroindústria, muitas vezes beneficiada indireta e indevidamente com o crédito oficial. Favorece também os mediadores no interior do assentamento - aqueles assentados que se põem como agentes das negociações ou de determinadas tarefas no ciclo produtivo.

A cana pode significar um bom dinheiro recebido anualmente, enquanto na outra metade do lote se consegue a manutenção da agricultura familiar, a diversificação agrícola que os provê de alimento e de renda através da venda do excedente, situação que não pode ser generalizada. Há exemplos, mesmo que restritos, de assentados que produzem hortaliças e legumes e têm estruturas de horta no lote que lhes garantem o autoconsumo e renda através da venda direta e da participação em programas municipais. O dinheiro advindo da horta garante a renda do dia-a-dia, enquanto o da cana garante uma renda anual para investimento na horta e demais atividades do lote.

Como dito anteriormente, as variações demográficas da família, a mão-de-obra disponível e a capacidade de investir em insumos são fatores que variam de um lote para outro. Os que compram insumos e os aplicam, fazem a carpa, cuidam da cana em seu lote não podem ser colocados como arrendatários, pois mesmo com todas as características da parceria eles têm trabalho no canavial e fazem um balanço de investimentos e esforços necessários. Por outro lado, existem muitos lotes que são totalmente arrendados, seja pela composição familiar carente de braços ou em função da pluriatividade, sobretudo através do assalariamento fora do assentamento.

Tal situação tem desdobramentos no campo dos direitos trabalhistas e previdenciários. Depoimentos de assentados que recebiam auxílio doença e que passaram a ter sustados tais direitos revelam que o Sindicato 
de Empregados Rurais de Araraquara passou a dificultar o fornecimento de declarações da atividade exigida para recebimento do beneficio da previdência social.

\section{$7 \mathrm{O}$ balanço positivo dos programas municipais de segurança alimentar no município de Araraquara-SP: alternativas possíveis de políticas públicas às parcerias}

Pelos dados do LUPA (2008) pode ser observado que a maior quantidade de UPAs existentes no município de Araraquara-SP (79\%) possui uma área inferior a 50 ha, que é inversamente proporcional à área total existente, já que as propriedades com mais de 100 ha, em número de $12 \%$, ocupam $76 \%$ da área total, compreendendo 904 UPAs. Estão dentro deste recorte produtores localizados nos bairros rurais e nos assentamentos rurais, sendo este último grupo o mais numeroso. A produção agrícola familiar no município de Araraquara provém, portanto, principalmente, dos agricultores familiares assentados, em sua maioria, altamente descapitalizados e carentes de apoio institucional.

Nesse município, como uma forma de contemplar a agricultura familiar de assentados e pequenos produtores rurais na agenda municipal, a prefeitura desenvolveu parceria com o Governo Federal com dois objetivos: 1) venda direta, dos produtores aos consumidores locais (Programas de Feira do Produtor, Direto do Campo, Programa de Aquisição de Alimentos Locais do Governo Federal); 2) integração das produções de alimentos da agricultura familiar em projetos de mercado institucional (como a alimentação escolar, o restaurante popular e o banco de alimentos). As análises dos resultados dessas ações parecem apontar perspectivas que podem levar os agricultores familiares à inclusão social, por meio de uma agenda política de segurança alimentar local.

As políticas de segurança alimentar do município de Araraquara funcionam sob uma rede de coordenação centralizada. A prefeitura do município criou um órgão para coordenar os programas de segurança alimentar local e centralizar a(s) rede(s) a ela ligada(s). Esta se tornou pertinente em um contexto em que a cidade de Araraquara passa a se inscrever em vários editais do MDS - Ministério de Desenvolvimento Social - com a finalidade de obter financiamentos para um conjunto de iniciativas que visam inclusões de pessoas produtivas (da agricultura familiar até as hortas urbanas) para a geração de alimentos que possam atingir pessoas em estados de insegurança e segurança alimentar.

A Coordenadoria de Agroindústria e Segurança Alimentar está submetida à Secretaria de Desenvolvimento do município. Da mesma forma, estão submetidas à Coordenadoria três gerências: Agricultura, Merenda Escolar e Abastecimento e, por último, a de Abastecimento Institucional Geral, cada uma responsável por um conjunto de programas.

No caso específico do município de Araraquara, há um conjunto de políticas de segurança alimentar que interagem e, ao mesmo tempo, se complementam, formando uma rede de conexões primárias e secundárias. A proposta de gestão centralizada dos programas permite uma maior dinâmica em relação aos produtos recebidos pelo PAA, agente dinamizador da rede e do destino dos mesmos. Os produtos do PAA são destinados ao Banco de Alimentos e posteriormente a entidades e escolas municipais. Alguns produtos recebem um préprocessamento ou um preparo final nos programas da gerência de abastecimento geral, antes de serem enviados aos destinos finais (escolas, entidades e Restaurante Popular), compondo a rede primária de segurança alimentar do município.

Também existe o Programa Direto no Campo e outras iniciativas isoladas da rede primária que apresentam resultados significativos, ainda que tímidos, de inclusão social e desenvolvimento regional. A transformação da comercialização dos produtos em uma feira de agricultores familiares passa a ter um caráter de comprometimento político com a aprovação da lei 5908/2001, em outubro de 2001, quando foram instaladas as primeiras bancas no terminal de integração de ônibus urbano e no Paço Municipal. Atualmente, o programa Direto do Campo ou Varejão Popular, no Município de Araraquara, é operacionalizado através de três iniciativas em que entram cerca de 100 mulheres e homens assentados em uma rede, da qual participam distintos atores. 


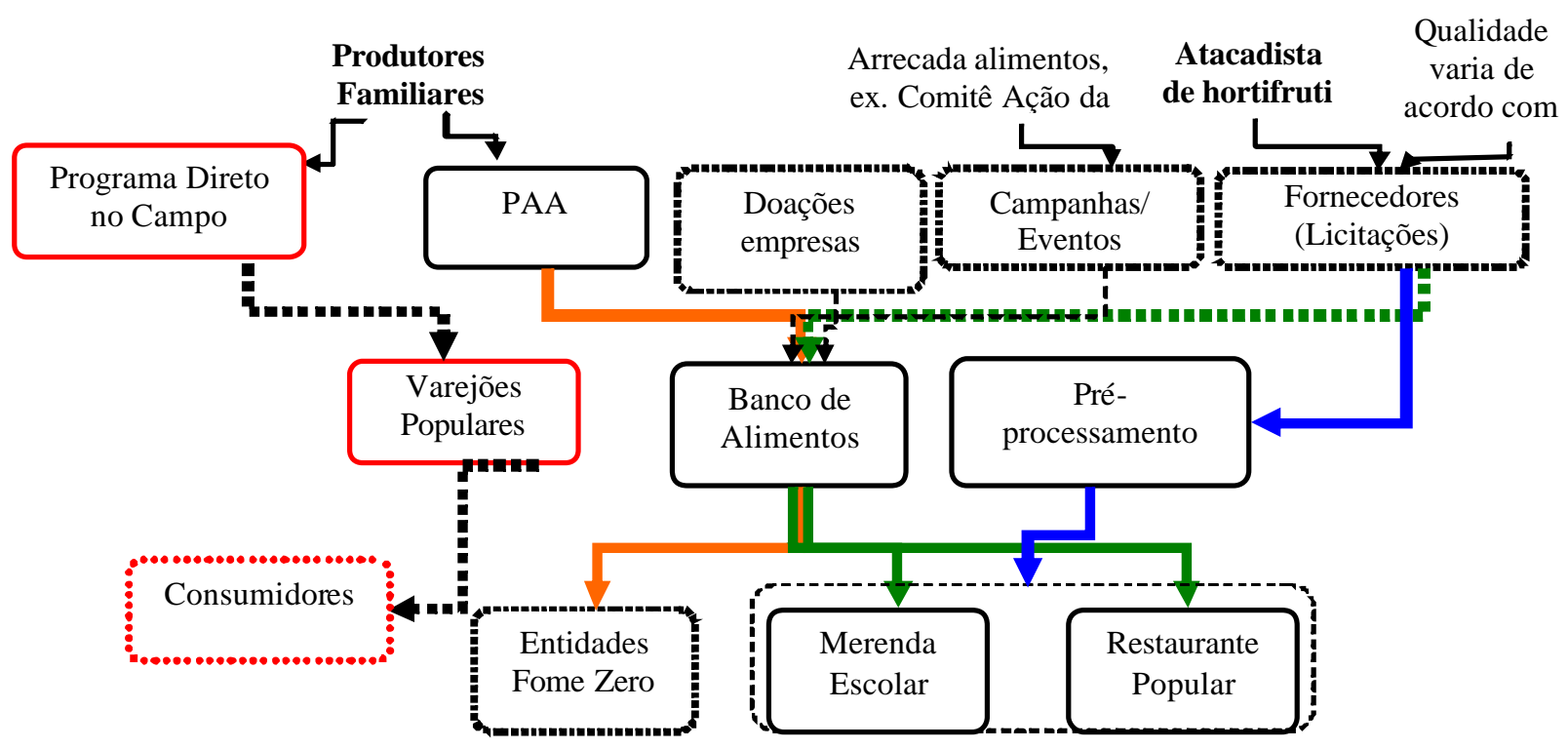

Figura 1 - Rede Política de Segurança Alimentar no Município de Araraquara-SP.

Fonte: ALMEIDA, 2008.

O envolvimento dos produtores assentados nesses programas - o que lhes permite sair do circuito de dependência dos atravessadores no processo de comercialização - a melhoria de qualidade da alimentação escolar podem ser embriões de um modelo alternativo de desenvolvimento rural, o que merece, sem dúvidas, atenção e acompanhamento.

\section{O biodiesel como "salvação" dos assentamentos do Pontal}

A implantação de uma política nacional de biodiesel que define o segmento da agricultura familiar como sua principal base de fornecimento de matéria-prima projeta impactos ainda não claramente avaliados nos assentamentos rurais, implicando novas estratégias e conflitos no encaminhamento das experiências de reforma agrária. No Estado de São Paulo, a adesão ao projeto de fornecimento de oleaginosas para a produção de biocombustíveis ainda tem um caráter um tanto incipiente, já que não foi instalada qualquer planta industrial processadora de matéria-prima. No entanto, divergências e concorrências têm marcado a discussão dessa alternativa.

Se, na região de Araraquara, na qual há mais tempo tem-se a cana nos assentamentos, a produção para o biodiesel não passou até hoje de projeto nos discursos políticos, no Pontal do Paranapanema, por outro lado, uma iniciativa concreta - embora bastante problemática - fez com que centenas de assentados já tenham, no ano de 2008, produzido e vendido mamona para a produção do combustível.

Em rota de colisão com a direção nacional do Movimento dos Trabalhadores Sem-Terra (MST) desde o final do governo FHC, a principal liderança dos sem-terra na região (José Rainha Júnior) segue efetivamente, com seu grupo de militância, como principal referência da luta pela terra na região. Excluído da organização nacional, essa fração mantém a bandeira, o "método" e a denom inação do $\mathbf{M}$ ovim ento 8 . Este grupo tem buscado construir uma alternativa institucional à cooperativa (COCAMP - outrora sob a direção do grupo de Rainha Júnior), direcionando seus esforços na montagem de uma entidade legalmente constituída, a fim de também concorrer às verbas federais destinadas aos assentamentos do Pontal. Surge em 2006, então, a Federação das Associações de Agricultores Familiares do Pontal do Paranapanema (FAAFOP), com sede no município de Mirante do Paranapanema vizinho de Teodoro Sampaio, sede da COCAMP. Registros da imprensa regional dão conta de um relativo sucesso desta nova entidade, que foi apontada, em 2007, como 
a que mais recebeu recursos dos vários programas do governo federal destinados a atender sem-terras e assentados rurais.

Como principal projeto da FAAFOP para o desenvolvimento dos assentamentos no Pontal está a produção de cultivares para a industrialização do biodiesel. Certamente, boa parte dos recursos federais recebidos pela entidade foi investida no fomento da produção de oleaginosas nos assentamentos. Nas palavras de José Rainha Júnior na imprensa regional, o biodiesel seria "a salvação" da reforma agrária no Pontal do Paranapanema.

Dados divergentes são ventilados acerca dessa experiência de produção para o biodiesel no Pontal. Dirigentes da FAAFOP falam em 2000 assentados envolvidos no projeto (distribuídos em vários assentamentos da região). Outras lideranças dos assentamentos calculam em centenas os produtores assentados que efetivamente se engajaram nessa alternativa. O certo é que, embora o "MST/Pontal" busque financiamentos para a instalação de uma planta industrial de produção do biodiesel no Pontal, os assentados - mediados pela Federação e por uma nova cooperativa (Cooperativa de produção de Biodiesel do Oeste Paulista Cooperbioeste) - tiveram que negociar a mamona colhida nos assentamentos em 2008 para uma indústria do Mato Grosso do Sul.

A novidade e o caráter recente desta alternativa impede que se faça uma discussão acerca de sua viabilidade. No entanto, constata-se que a disseminação da mamona nos assentamentos do Pontal foi notável em abrangência geográfica. Além disso, cerca de cem produtores se concentram num único assentamento - a "Gleba XV de Novembro", maior assentamento do Pontal, com mais de 500 lotes produtivos. Dados preliminares dão conta de que praticamente todas as operações de plantio e colheita da mamona foram subsidiadas pela FAAFOP/Cooperbioeste. Por outro lado, assentados se queixam de que não conseguiram "entregar" a mamona - ou seja, a entidade fomentadora não conseguiu recolher toda a produção, distribuída por assentamentos muito distantes uns dos outros.

As críticas, no entanto, vão além das dificuldades logísticas e do caráter altamente subsidiado da produção para o biodiesel.
Com a defesa dessa alternativa produtiva para os assentamentos, a fração do MST liderada por Rainha Júnior estabelece uma clara divergência ideológica com a organização nacional dos sem-terra - frontalmente contrária aos biocombustíveis.

\section{Repensando problemas: o que desponta no horizonte?}

Os impactos da expansão da cana não podem ser analisados como um movimento de mão única, como impulsionadores da dinâmica regional ou como geradores únicos de renda à população assentada. A partir do controle do espaço pelos usineiros, a gestão que os assentados puderam imprimir ao território dos assentamentos, nos aspectos de sua mobilização e participação econômica ficou, em princípio, prejudicada.

A própria eleição direta dos representantes do assentamento acabou sofrendo solução de continuidade (no caso do assentamento Bela Vista do Chibarro). Praticamente foi cassada a liberdade de escolha dos assentados que passam a ter seu espaço "vigiado" por outros. A associação que se afirmava defensora da parceria com as usinas (P.A. Bela Vista do Chibarro) foi perdendo legitimidade no processo.

Nos contratos firmados com as agroindústrias há uma assimetria de informações. Os assentados desconhecem as fórmulas de previsão da safra, de preço da cana - as quais são de domínio de agentes contratados pelos usineiros - o que os leva a ficar, de fato, de fora do processo. Os assentados não conseguem saber o valor real de sua produção, o que foi gasto, a quantidade e qualidade dos insumos, a pesagem da cana e, muito menos, como esta produção entra no circuito nacional e internacional de expansão da cana. Tais incertezas estão presentes nas falas dos assentados das duas regiões. Há cláusulas nos contratos que impedem os assentados de qualquer resistência legal aos usineiros, o que cristaliza, efetivamente, uma relação de assimetria.

Na vivência desta experiência, ao aceitar a parceria da cana, os assentados passaram a enfrentar outros problemas e os riscos de se verem, de fato, em situação "cativa". É preciso igualmente que se diga que não tem 
havido no campo das políticas públicas dirigidas a assentamentos, reais oportunidades e/ou alternativas que se contraponham à expansão da cana, com poucas exceções. A própria perspectiva de revitalização da diversificação agrícola acaba sendo afetada, embora não se possa dizer que a mesma saiu de cena, podendo, em principio, garantir estratégias de permanência na terra, com maior liberdade de decisão familiar.

Dados observados na produção das famílias têm revelado expressões dessa diversidade (criação de capivaras e agroindustrialização de buchas de banho no Pontal, criação de frangos e fruticultura na região de Araraquara). Neste caso, as práticas agrícolas mantêm elos com os conhecimentos tradicionais, os quais são "dispensados" na cultura canavieira.

Há outras situações a considerar. $\mathrm{Na}$ região de Araraquara, como uma forma de contemplar os assentamentos na agenda municipal, existem, como já afirmado, programas da Prefeitura, eventualmente em parcerias com outras esferas do governo, que absorvem parte da produção existente. Tais iniciativas devem ser investigadas como um embrião de modelo de desenvolvimento alternativo às economias regionais.

Em Araraquara, o Incra mudou, no discurso, sua forma de gestão, mas na prática, há muitas indefinições. A tentativa, por parte do Sindicato dos Empregados Rurais, de um novo modelo de agricultura baseado nos moldes de prevenção e proteção ambiental sem certeza das formas de viabilizá-lo reforça inseguranças. Nos núcleos da Fazenda Monte Alegre, apesar da resistência à cana se manifestar em muitas famílias, a mediação do Itesp ainda é pautada por ambiguidades. Ocorreram, no entanto, mudanças. Com a recente falência da Usina Santa Luizà, os assentados foram divididos em três grupos: os núcleos 1 e 5 têm contratos com a Usina Bonfim, do grupo COSAN que fica em Guariba; núcleos 2 e 4 com a Usina São Martinho, que fica em Pradópolis e núcleos 3 e 6 com as Usinas Santa Cruz (Américo Brasiliense) e Maringá (Araraquara). A disputa de quatro usinas em torno da produção nos assentamentos da Fazenda Monte Alegre mostra que a parceria com os assentados está longe de ser um negócio ruim, fadado ao fracasso.
No Pontal do Paranapanema, relações de clientelismos se alternam com situações de proximidade e de distanciamento com o MST, com as indefinições da Prefeitura, com as estratégias de mobilização buscadas pelos assentados produtores familiares de leite em uma construção de outro modelo de desenvolvimento rural. Lá, também, as incertezas da produção para o biodiesel se mesclam com a ameaça de ampliação da área plantada de cana para as destilarias. Além disso, a defesa do biodiesel marca a principal divergência programática entre o MST nacional e o MST/Pontal.

Passamos em revista estratégias e projetos os quais colocam, frente a frente, as possibilidades da agricultura familiar e o monopólio do agronegócio nos sistemas produtivos e na economia regional.

Cabe a nós, investigadores, analisar alternativas e rumos dessas experiências de Reforma Agrária, os quais não podem ser discutidos sem ser passada em revista, em profundidade, a trama de tensões presentes nos paradoxos da integração do assentamento aos complexos agroindustriais e na difícil, mas possível, perspectiva de um modelo de desenvolvimento alternativo e sustentável.

\section{Notas}

${ }^{1}$ Leve-se em conta que, em função mesmo desse entorno socioeconômico, a maioria das famílias assentadas na região tem uma trajetória recente de trabalho imediatamente ligada a essa economia agroindustrial - 70\% no P.A. Monte Alegre e cerca de $50 \%$ na Bela Vista (cf. FERRANTE e BERGAMASCO, 1995).

2 Estão excluídos deste montante os assentados em projetos de responsabilidade do governo federal, como os abaixo citados P.A.s Bela Vista do Chibarro (Araraquara) e Água Sumida (Teodoro Sampaio).

${ }^{3}$ Neste artigo, não serão considerados para análise os assentamentos sob jurisdição dos Grupos Técnicos de Campo (Itesp) de Bebedouro e Rosana, assim como os P.A.s Santa Zélia e Santa Cruz da Alcídia (GTC de Teodoro Sampaio), cuja implantação da cana é mais recente.

${ }^{4}$ Tal situação refere-se à proposta da Destilaria Alcídia a respeito da implantação da cultura da cana nos assentamentos do Pontal do Paranapanema. Secretaria da Justiça e Defesa da Cidadania/Instituto de Terras/ DAF, São Paulo, s/d.

${ }^{5}$ A Unesp emitiu um parecer técnico, a pedido do ITESP, em 1995.

${ }^{6}$ Conforme Leal (2003), a Destilaria Alcídia teria garantido benfeitorias (como roda d'água, estradas e material de construção) aos assentados, quando da 
implantação do P.A.

${ }^{7}$ Depoimento de um ex-diretor do ITESP (hoje funcionário do INCRA), colhido em 2004.

${ }^{8}$ O grupo de José Rainha Júnior se intitula como “Movimento Sem-Terra do Pontal do Paranapanema" ou "MST/Pontal".

${ }^{9}$ A Usina Santa Luiza, no município de Motuca, era a receptora da cana plantada no P.A. Monte Alegre.

\section{Referências}

ANTONIO, A. P. O movimento social e a organização do espaço rural nos assentamentos populacionais dirigidos pelo estado. Os exemplos da alta sorocabana no período $1960-$ 1990. 1990. Tese (Doutorado em Geografia) - FFLCHUSP, São Paulo, 1990.

BARONE, L. A. Revolta, conquista e solidariedade: a economia moral dos trabalhadores rurais em três tempos. 1996. Dissertação (Mestrado em Sociologia) FCL/UNESP, Araraquara, 1996.

Assistência técnica aos assentamentos de reforma agrária: da política reativa ao vazio de projeto - o caso do Estado de São Paulo. Retratos de Assentamentos, Araraquara: FCL/UNESP, n. 8, 2000.

BAÚ, C. H. R. Pequenos produtores fornecedores de canade-açúcar na Região de Araraquara (SP): uma estratégia de produção e sobrevivência no assentamento Bela Vista do Chibarro. 2002. Dissertação (Mestrado em Sociologia) - FCL/UNESP, Araraquara, 2002.

BOTASIM, R. S. Trabalhador sem-terra assentado: umfuturo pequeno capitalista? - estudo do assentamento Água Sumida no município de Teodoro Sampaio/SP. 2002. Monografia (Bacharelado em Geografia) - FCT/UNESP, Presidente Prudente, 2002.

BOURDIEU, Pierre. O poder simbólico. Rio de Janeiro: Bertrand e Brasil, 1989.

CANDIDO, A. Os parceiros do Rio Bonito. 7. ed. São Paulo: Duas Cidades, 1987.

FERNANDES, B. M.MST: formação e territorialização. São Paulo: Hucitec, 1996.

FERRANTE, V. L. S. B. A chama verde dos canaviais. 1992. Tese (Livre Docência) - UNESP, Araraquara, 1992.

FERRANTE, V. L. S. B.; WHITAKER, D. C. A.; BARONE, L. A. Poder local e assentamentos rurais; expressões de conflito, de acomodação e de resistência. Projeto de Pesquisa (CNPq). Araraquara/Presidente Prudente, Nupedor/GEPEP, 2003.

FERRANTE, V. L. S. B.; ALY JUNIOR, O. (Orgs.). Assentamentos rurais: impasses e dilemas (uma trajetória de 20 anos). São Paulo: INCRA/Uniara, 2005.

FERRANTE, V. L. S. B.; BERGAMASCO, S. M. P. P. (Orgs.). Censo de assentamentos rurais do estado de São Paulo. Pesquisa Multicamp/UNESP - Análise e Avaliação dos Projetos de Reforma Agrária e Assentamentos do Estado de São Paulo. Dezembro/1995.
FERRANTE, V. L. S. B.; BARONE, L. A. Homens e mulheres nos assentamentos: violência, recusa e resistência na construção de um novo modo de vida. Revista Perspectivas, São Paulo: EDUNESP, v. 20/21, 1997/1998.

FERRANTE, V. L. S. B.; SANTOS, M. P. dos. A cana nos assentamentos: novas roupagens, velhas questões. In: CONGRESSO DA SOBER, 42. Anais..., Juiz de Fora, julho, 2003. CD Room.

FERREIRA JÚNIOR, A. C. Ações e políticas públicas para o desenvolvimento dos assentamentos Santa Terezinha da Alcídia e Alcídia da Gata em Teodoro Sampaio/SP. 2007. Monografia (Bacharelado em Geografia) - FCT/UNESP, Presidente Prudente, 2007.

LEAL, G. M. Impactos socioterritoriais dos assentamentos rurais do município de Teodoro Sampaio/SP. 2003. Monografia (Bacharelado em Geografia) - FCT/UNESP, Presidente Prudente, 2003.

LEITE, J. F. A ocupação do Pontal do Paranapanema. São Paulo: Hucitec, 1998.

LIMA, E. C. Os movimentos sociais de luta pela terra e pela reforma agrária no Pontal do Paranapanema (SP): dissidências e dinâmica territorial. 2006. Dissertação (Mestrado em Geografia) - FCT/UNESP, Presidente Prudente, 2006.

MEDEIROS, L.S. de; LEITE, S. (Orgs.). Assentamentos rurais. Mudança social e dinâmica regional. Rio de Janeiro: Mauad, 2004.

NEVES, D. P. Assentamentos rurais - reforma agrária em migalhas. Niterói: EDUFF, 1997.

Lavradores e pequenos produtores de cana. Rio de Janeiro: Zahar, 1981.

PINASSI, M. O.; QUEDA, O. Consórcio canavieiro: proposta inovadora ou reedição de práticas tradicionais? Revista de Reforma Agrária, Campinas: ABRA, n. 2, v. 23, maio/ago. 1993.

PORTARIA ITESP - 75, de 24/10/2002 - Diário Oficial do Estado - Fundação Instituo de Terras do Estado de São Paulo “José Gomes da Silva”, 2002.

PUTNAN, R. D. Comunidade e democracia. A experiência da Itália Moderna. Rio de Janeiro: Ed. FGV, 2000.

RAMOS, P. Relatório de contrato de prestação autônoma de serviços técnicos especializados de consultoria - quarto relatório (PROCESSO 15000/2005 - CONVÊNIO INCRA - ATES). Campinas, Outubro/2005.

STETTER, E. A. A cana nos assentamentos rurais: presença indigesta ou personagem convidada? 2000. Dissertação (Mestrado em Sociologia) - UNESP/FCLAR, 2000.

WHITAKER, D. C. A. A questão da diversidade em assentamentos de reforma agrária: Araraquara/SP. In: BERGAMASCO, S. M. P. P. et al. Dinâmicas familiar, produtiva e cultural nos assentamentos rurais de São Paulo. Araraquara: UNIARA; Campinas: FEAGRI/ UNICAMP; São Paulo: INCRA, 2003. 